\title{
The potential of wind and solar energy in Malaysia east coast: preliminary study at Universiti Malaysia Pahang (UMP)
}

\author{
A. K. Amirruddin ${ }^{1}$, M. M. Noor ${ }^{2}$, K. Kadirgama ${ }^{1}$ \\ \& K. V. Sharma ${ }^{1}$ \\ ${ }^{I}$ Universiti Malaysia Pahang, Faculty of Mechanical Engineering, \\ Pekan, Malaysia \\ ${ }^{2}$ Computational Eng. \& Science Research Centre, \\ University of Southern Queensland, Australia
}

\begin{abstract}
The main objective of this article is to investigate wind and solar potential in Universiti Malaysia Pahang renewable energy resources as response to Malaysian government regarding to green technology. It is a preliminary study mainly focuses on technique of measurement and collecting potential wind and solar data. The first solar panels installation was planned to be inside Universiti Malaysia Pahang with the first wind turbine being installed at the bank of the Sungai Pahang in Pekan, Pahang. The local solar radiation regime was described with on-site measurements and calculations where the former was carried out from the beginning of 2010. The setup of the measurement device is discussed in this paper.

Keywords: wind energy, solar energy, green technology.
\end{abstract}

\section{Introduction}

Future Higher energy demand and lower supply of fosil fuel and coal for energy cause many research toward renewable energy. Solar Energy is one of the best renewable energy resources. The Earth receives 174 petawatts (PW) of incoming solar radiation (insolation) at the upper atmosphere [1]. Approximately $30 \%$ is reflected back to space while the rest is absorbed by clouds, oceans and land masses. The spectrum of solar light at the Earth's surface is mostly spread across 
the visible and near-infrared ranges with a small part in the near-ultraviolet [2]. Earth's land surface, oceans and atmosphere absorb solar radiation, and this raises their temperature. Warm air containing evaporated water from the oceans rises, causing atmospheric circulation or convection. When the air reaches a high altitude, where the temperature is low, water vapor condenses into clouds, which rain onto the Earth's surface, completing the water cycle. The latent heat of water condensation amplifies convection, producing atmospheric phenomena such as wind, cyclones and anti-cyclones [3]. Sunlight absorbed by the oceans and land masses keeps the surface at an average temperature of $14^{\circ} \mathrm{C}$ [4]. By photosynthesis green plants convert solar energy into chemical energy, which produces food, wood and the biomass from which fossil fuels are derived [5]. Solar energy refers primarily to the use of solar radiation for practical ends. However, all renewable energies, other than geothermal and tidal, derive their energy from the sun.

Solar technologies are broadly characterized as either passive or active depending on the way they capture, convert and distribute sunlight. Active solar techniques use photovoltaic panels, pumps, and fans to convert sunlight into useful outputs. Passive solar techniques include selecting materials with favorable thermal properties, designing spaces that naturally circulate air, and referencing the position of a building to the Sun. Active solar technologies increase the supply of energy and are considered supply side technologies, while passive solar technologies reduce the need for alternate resources and are generally considered demand side technologies [6]. Malaysia lies entirely in the equatorial region. The tropical environment has been characterized by heavy rainfall, constantly high temperature and relative humidity. The annual average daily solar irradiations for Malaysia were from $4.21 \mathrm{kWh} / \mathrm{m}^{2}$ to $5.56 \mathrm{kWh} / \mathrm{m}^{2}$. The highest solar radiation was estimated at $6.8 \mathrm{kWh} / \mathrm{m}^{2}$ in August and November while the lowest was $0.61 \mathrm{kWh} / \mathrm{m}^{2}$ in December. The Northern region and a few places in East Malaysia have the highest potential for solar energy application due to its high solar radiation throughout the year [7].

\section{Goals}

There are three goals outlined by Malaysian government regarding on green technology. The three goals are [8]:

\subsection{Short-term goals $\left(10^{\text {th }}\right.$ Malaysia Plan)}

-Increase public awareness and commitment for the adoption and application of Green Technology through advocacy programmed;

-Widespread availability and recognition of Green Technology term of products, appliances, equipment and systems in the local market through standards, rating and labeling programmed;

-Increased foreign and domestic direct investments (FDIs and DDIs) in Green Technology manufacturing and services sectors; and 
-Expansion of local research institutes and institution of higher learning to expand Research, Development and Innovation activities on Green Technology towards commercialization through appropriate mechanisms.

\subsection{Mid-term goals $\left(11^{\text {th }}\right.$ Malaysia Plan)}

-Green Technology becomes the preferred choice in procurement of products and services;

-Green Technology has a larger local market share against other technologies, and contributes to the adoption of Green Technology in regional markets;

-Increased production of local Green Technology products;

-Increased Research Development and Innovation of Green Technology by local universities and research institutions and are commercialized in collaboration with the local industry and multi-national companies;

-Expansion of local SMEs and SMIs on Green Technology into the global market; and

-Expansion of Green Technology applications to most economic sectors.

\subsection{Long-term goals (12 ${ }^{\text {th }}$ Malaysia Plan)}

-Inculcation of Green Technology in Malaysian culture; Widespread adoption of Green Technology reduces overall resource consumption while sustaining national economic growth;

-Significant reduction in national energy consumption;

-Improvement of Malaysia's ranking in environmental ratings;

-Malaysia becomes a major producer of Green Technology in the global market; and

-Expansion of international collaborations between local universities and research institutions with Green Technology industries.

The goals indicated that Malaysia governments very seriously look into green technology. It is hoped that after the installation of the first wind turbine in Pekan, interest will increase and an attempt will be made to manufacture in some parts in Malaysia.

\section{Research}

The Faculty of Mechanical Engineering of University Malaysia Pahang has been carrying out research on the use of solar energy and measuring solar energy potential in Pekan. University Malaysia Pahang will be monitoring solar radiation and solar energy over a 1-year period. The structure of measurement equipment is shown in Figure 1. The tallest building in University Malaysia Pahang was selected to install the wind tower; this will eliminate any blockage by other building. Structure is designed with $6 \mathrm{~m}$ height and the basement of structure is screwed with the building cement base. Top of the structure wireless sensor was installed. This wireless sensor (300 m line of sight) will transmit the reading to a Weatherlink data logger which kept inside a room. Block diagram of the system transmit is shown in Figure 2. Sensor is powered by solar energy and 
lithium battery provides back up at night and during cloudy. Temperature and humidity sensors are located inside the radiation shield. The shield protects the sensors from solar radiation and other sources of radiated and reflected heat. It also included with rain collector where meets the guidelines of the World Meteorological Organization, with reads rainfall amount in 0.01 to $0.2 \mathrm{~mm}$ increments. The data collected every $10 \mathrm{~min}$ and then average it for 1 day. The latitude of the point where wind tower fixed $\left(3^{\circ} 32^{\prime} 17^{\prime \prime}\right.$ is measured with GPRS system.

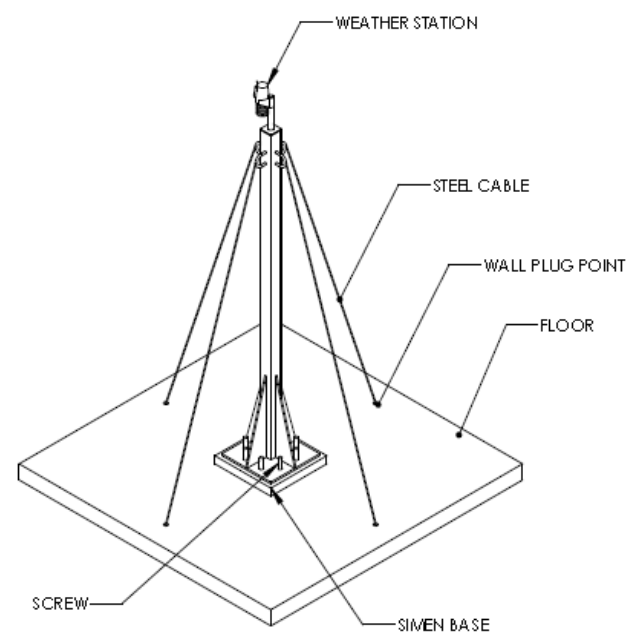

Figure 1: Wind tower structure.

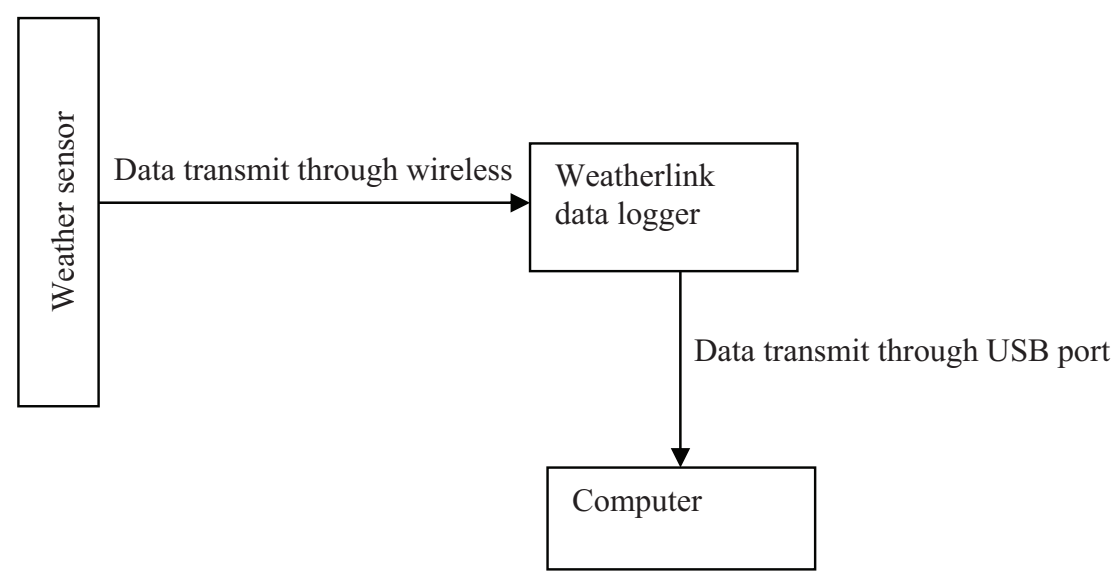

Figure 2: Schematic diagram for measuring solar energy. 


\section{Result and discussion}

The preliminary data for month of June is shown in Figure 3 and Figure 4, where it indicated that average solar radiation is around $982 \mathrm{~W} / \mathrm{m}^{2}$ and solar energy around $400 \mathrm{Ly}$. The highest solar radiation reached up to $1200 \mathrm{~W} / \mathrm{m}^{2}$ as shown in Figure 5. June is the hot session in Pekan since the temperature show that it can reached around 30 to $33^{\circ} \mathrm{C}$ as shown in Figure 6 . High temperatures $\left(32 \sim 33^{\circ} \mathrm{C}\right)$ occur at $1.30 \mathrm{pm}$ to $4.30 \mathrm{pm}$, whereas temperatures drop to $25^{\circ} \mathrm{C}$ at $10.00 \mathrm{pm}$ onward. According to Markus et al. [9] favorable climatic conditions in the Northern parts of Spain, Italy, Croatia, in FYR of Macedonia, and around the Black Sea (Romania, Bulgaria and Turkey) with abundance of solar resource and

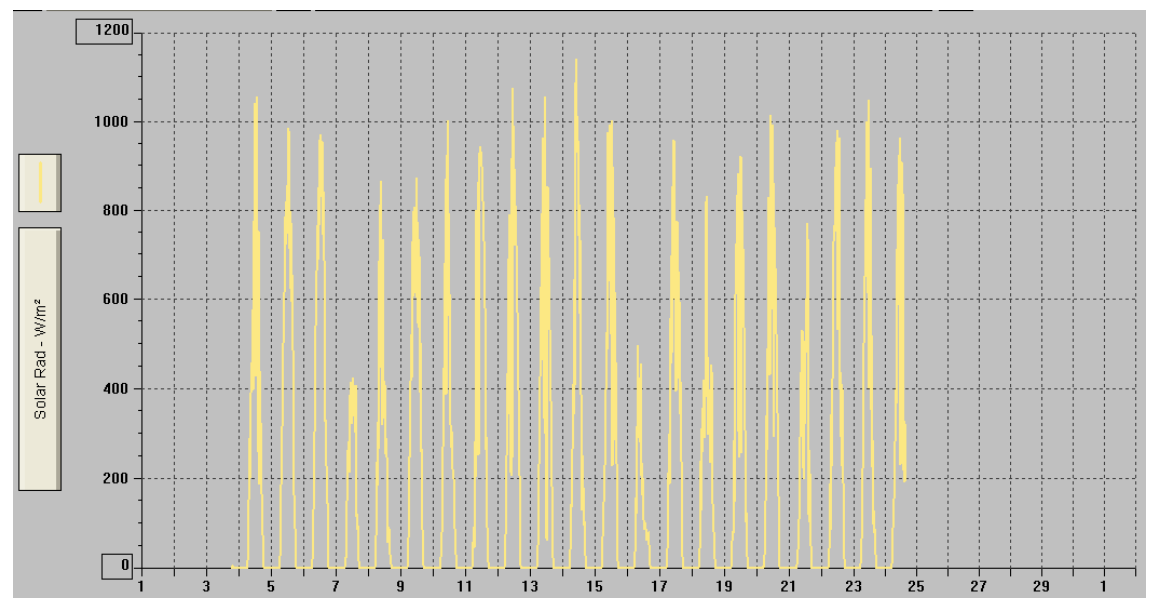

Figure 3: $\quad$ Solar radiation in the month of June.

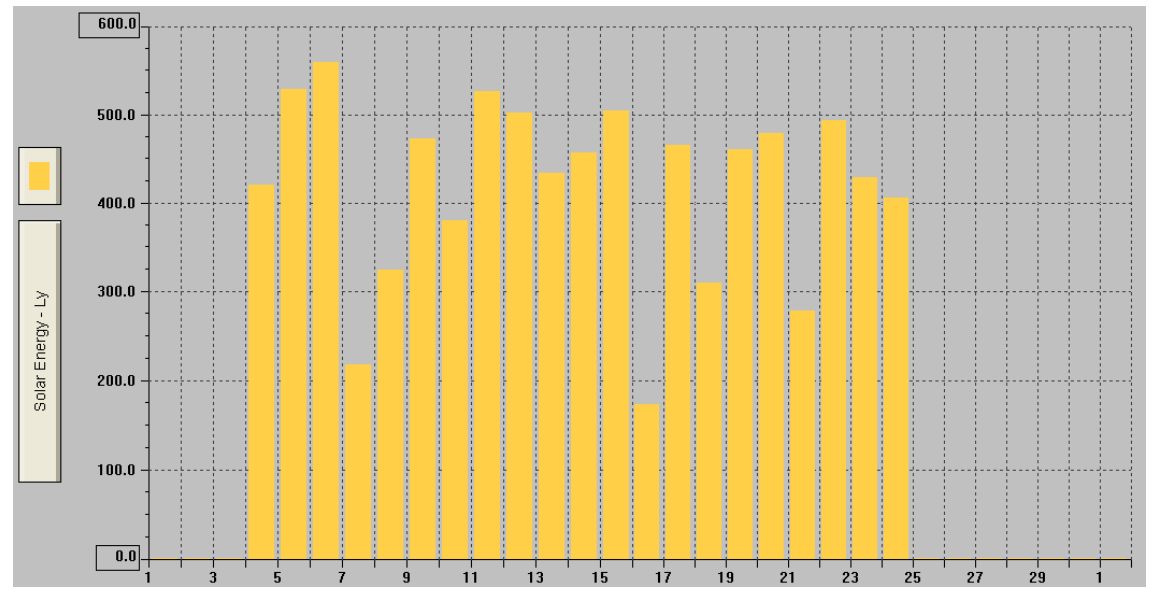

Figure 4: $\quad$ Solar energy in the month of June. 


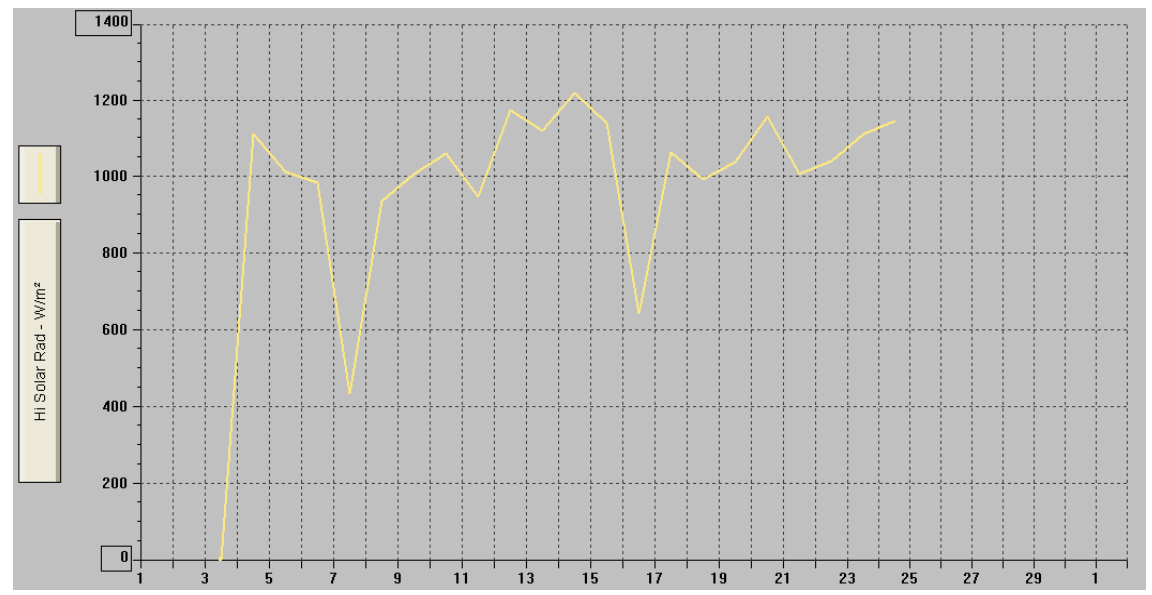

Figure 5: Highest solar radiation in the month of June.

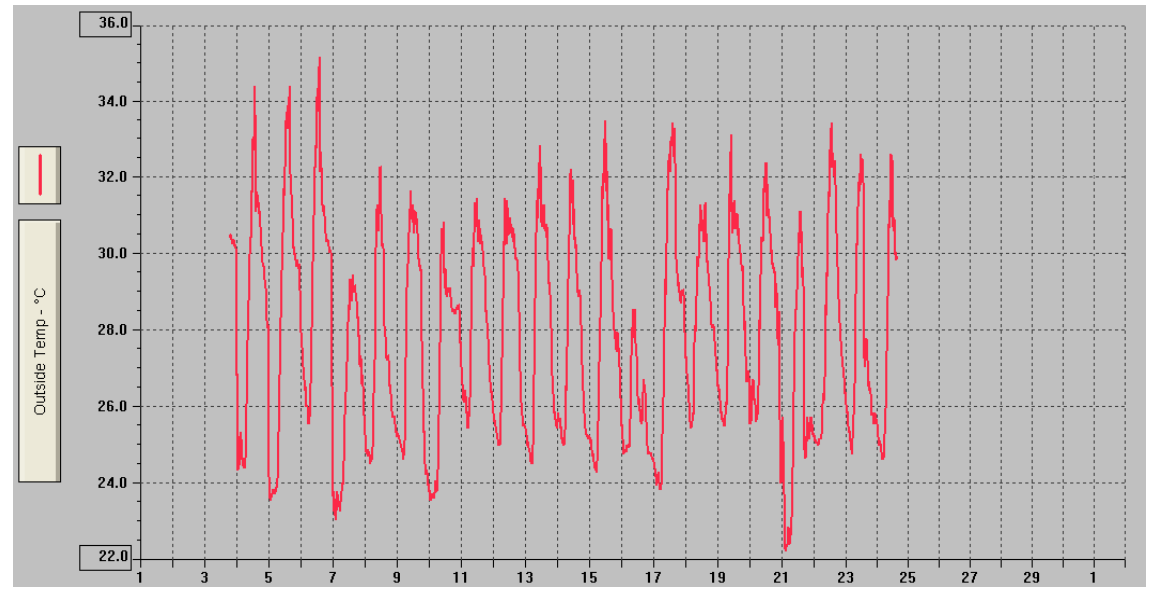

Figure 6: Temperature in the month of June.

PV potential in the range of $1000-1100 \mathrm{kWh} / \mathrm{kWp}$ per year. Good conditions are found in France (except in the North) and also in most regions of Central Europe (Hungary, Slovenia, Austria, Slovakia and Southern Germany) with more continental summers, where yearly generation usually falls into the range of $800-1000 \mathrm{kWh} / \mathrm{kWp}$ is estimated to be higher than $3.0 \mathrm{kWh} / \mathrm{m}^{2}$. Apart from that, a few areas in East Malaysia also shows the potential in solar energy application as these areas receive from average to very high solar radiation especially between May until November [7]. The lowest solar radiation estimated for East Malaysia is recorded in December until January. The solar radiation for east cost Malaysia is shown in Figure 7. 


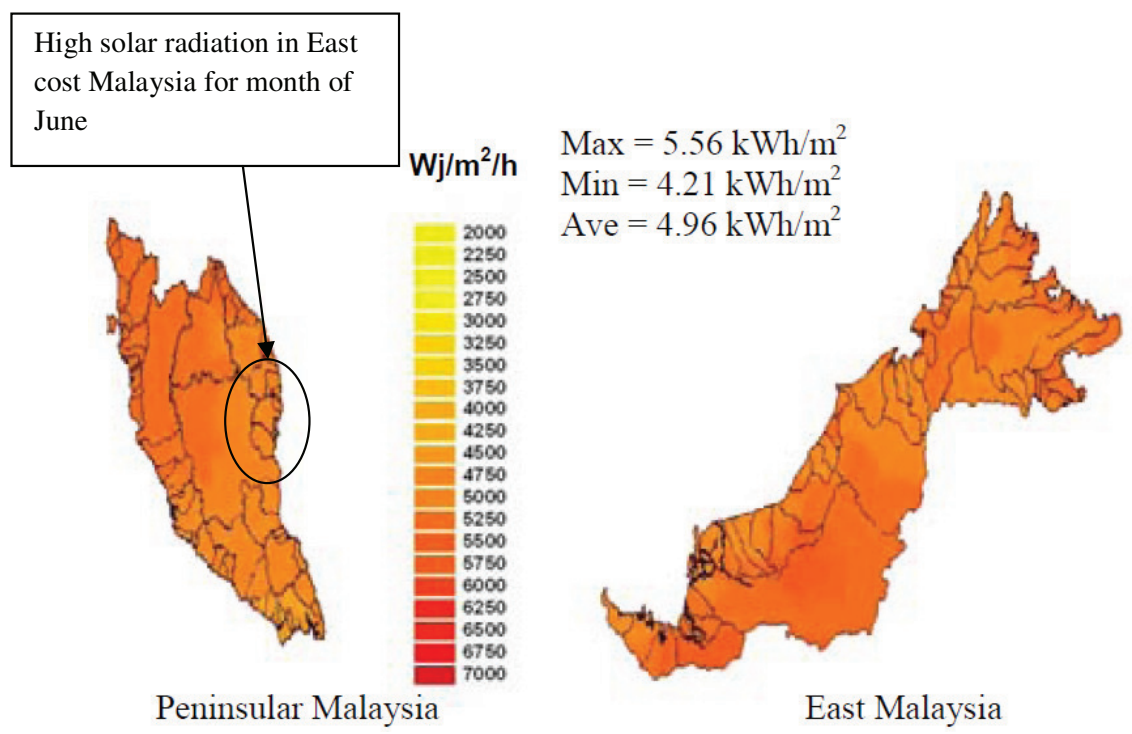

Figure 7: Average solar radiation in Malaysia in the month of June [7].

\section{Conclusion}

The study focused mainly on techniques of measurement and data collected was limited, thus it is hard to decide whether it will be suitable to install solar panel in Pekan, Pahang. As where the data available is concerned, the solar radiation during June in Pekan can reach around $982 \mathrm{~W} / \mathrm{m}^{2}$ with solar energy around 400 Ly. In short, this research is still in preliminary stage and needs more data to be evaluated before conclusions of potential solar energy in east coast of Peninsular Malaysia can be outlined and realized.

\section{Acknowledgement}

The authors would like to express their deep gratitude to Universiti Malaysia Pahang (UMP) for providing the laboratory facilities and financial support through research grant RDU0903126.

\section{References}

[1] Martin, Christopher L.; Goswami, D. Yogi (2005). Solar Energy Pocket Reference. International Solar Energy Society. ISBN 0977128202

[2] Mills, David (2004). "Advances in solar thermal electricity technology". Solar Energy 76 (1-3): 19-31 
[3] Agrafiotis, C.; Roeb, M.; Konstandopoulos, A.G.; Nalbandian, L.; Zaspalis, V.T.; Sattler, C.; Stobbe, P.; Steele, A.M. (2005). "Solar water splitting for hydrogen production with monolithic reactors". Solar Energy 79 (4): 409421

[4] Balcomb, J. Douglas (1992). Passive Solar Buildings. Massachusetts Institute of Technology Bradford, Travis (2006). Solar Revolution: The Economic Transformation of the Global Energy Industry. MIT Press. ISBN 026202604X

[5] Leon, M.; Kumar, S. (2007). "Mathematical modeling and thermal performance analysis of unglazed transpired solar collectors". Solar Energy 81 (1): $62-75$

[6] Tzempelikos, Athanassios; Athienitis, Andreas K. (2007). "The impact of shading design and control on building cooling and lighting demand". Solar Energy 81 (3): 369-382

[7] Ayu Wazira Azhari, Kamaruzzaman Sopian, Azami Zaharim, Mohamad Al Ghoul, "A New Approach For Predicting Solar Radiation In Tropical Environment Using Satellite Images - Case Study of Malaysia”, WSEAS Transactions on Environment and Development, 2007

[8] Malaysian Energy Department, 2010

[9] Marcel, Thomas A. Huld, Ewan D. Dunlop, Heinz A. Ossenbrink, 2007, "Potential of solar electricity generation in the European Union member states and candidate countries", Solar Energy, 81, 1295-1305 